\title{
Autoantibody profiling to identify biomarkers of key pathogenic pathways in mucinous ovarian cancer
}

\section{Citation}

Tang, Liangdan, Junzheng Yang, Shu-Kay Ng, Noah Rodriguez, Pui-Wah Choi, Allison Vitonis, Kui Wang, et al. 2010. "Autoantibody Profiling to Identify Biomarkers of Key Pathogenic Pathways in Mucinous Ovarian Cancer." European Journal of Cancer 46 (1) (January): 170-179. doi:10.1016/ j.ejca.2009.10.003.

\section{Published Version}

doi:10.1016/j.ejca.2009.10.003

\section{Permanent link}

http://nrs.harvard.edu/urn-3:HUL.InstRepos:27334949

\section{Terms of Use}

This article was downloaded from Harvard University's DASH repository, and is made available under the terms and conditions applicable to Other Posted Material, as set forth at http:// nrs.harvard.edu/urn-3:HUL.InstRepos:dash.current.terms-of-use\#LAA

\section{Share Your Story}

The Harvard community has made this article openly available.

Please share how this access benefits you. Submit a story.

\section{Accessibility}




\title{
AUTOANTIBODY PROFILING TO IDENTIFY BIOMARKERS OF KEY PATHOGENIC PATHWAYS IN MUCINOUS OVARIAN CANCER
}

\author{
Liangdan Tang ${ }^{1,2}$, Junzheng Yang ${ }^{1}$, Shu-Kay $\mathrm{Ng}^{3}$, Noah Rodriguez $^{1}$, Pui-Wah Choi $^{4}$, Allison \\ Vitonis $^{1}$, Kui Wang ${ }^{5}$, Geoffrey J. McLachlan ${ }^{5}$, Robert J. Caiazzo Jr. ${ }^{6}$, Brian C.-S. Liu ${ }^{6}$, William \\ R. Welch ${ }^{7}$, Daniel W. Cramer ${ }^{1}$, Ross S. Berkowitz ${ }^{1}$, and Shu-Wing Ng ${ }^{1,8}$ \\ ${ }^{1}$ Department of Obstetrics/Gynecology and Reproductive Biology, Brigham and Women's Hospital, \\ Boston, Massachusetts 02115, USA \\ ${ }^{3}$ School of Medicine, Griffith University, Meadowbrook, QLD4131, Australia \\ ${ }^{4}$ Department of Biochemistry, Chinese University of Hong Kong, Hong Kong, China \\ ${ }^{5}$ Department of Mathematics, University of Queensland, Brisbane, QLD4072, Australia \\ ${ }^{6}$ The Molecular Urology Laboratory, Division of Urology, Brigham and Women's Hospital, Boston, \\ Massachusetts 02115, USA. \\ ${ }^{7}$ Department of Pathology, Brigham and Women's Hospital, Boston, Massachusetts 02115, USA.
}

\begin{abstract}
Mucinous epithelial ovarian cancers are clinically and morphologically distinct from the other histopathologic subtypes of ovarian cancer. Unlike other ovarian subtypes, epidemiologic studies have indicated that tobacco exposure is a significant risk factor for developing mucinous ovarian cancer. Detection of autoantibody reactivity is useful in biomarker discovery and for explaining the role of important pathophysiologic pathways in disease. In order to study if there are specific antibody biomarkers in the plasma samples of mucinous ovarian cancer patients, we have initiated a screen by employing a "reverse capture antibody microarray" platform that uses native host antigens derived from mucinous ovarian tissues as "baits" for the capture of differentially labeled patient and control autoantibodies. 35 autoantibodies that were significantly elevated in the cancer plasma samples compared with healthy controls, and six autoantibodies that segregated smoking and nonsmoking patients were identified. Functional annotation of the antibody targets has identified nine target antigens involved in integrin and Wnt signaling pathways. Immunohistochemistry of archived ovarian specimens showed significant overexpression of eight of the nine target antigens in mucinous ovarian tumor tissues, suggesting that plasma autoantibodies from mucinous ovarian cancer patients might have heightened reactivities with epitopes presented by these overexpressed antigens. Autoantibody profiling may have an unexpected utility in uncovering key signaling pathways that are dysregulated in the system of interest.
\end{abstract}

\footnotetext{
(C) 2009 Elsevier Ltd. All rights reserved.

8To whom reprint requests should be sent: Shu-Wing Ng, Ph.D., Laboratory of Gynecologic Oncology, Brigham and Women's Hospital, 221 Longwood Avenue, Boston, MA 02115, USA. Fax: 1-617-975-0856; Tel: 1-617-278-0072; sng@ partners.org.

${ }^{2}$ Present address: Department of Obstetrics \& Gynecology, The First Affiliated Hospital of Chongqing Medical University, No.1 Yixue Yuan Road, Yuzhong District, Chongqing 400016, PR China.

Publisher's Disclaimer: This is a PDF file of an unedited manuscript that has been accepted for publication. As a service to our customers we are providing this early version of the manuscript. The manuscript will undergo copyediting, typesetting, and review of the resulting proof before it is published in its final citable form. Please note that during the production process errors may be discovered which could affect the content, and all legal disclaimers that apply to the journal pertain.
}

CONFLICT OF INTEREST STATEMENT Brian C-S. Liu serves as consultant for Inanovate, Inc. 


\section{Keywords}

Autoantibody; Ovarian cancer; smoking; profiling; signaling pathway

\section{INTRODUCTION}

Ovarian cancer accounts for more than half of the deaths due to gynecological malignancy (1). Because of lack of sensitive tests for the detection of early stage disease, which is often without prominent symptoms, $75 \%$ of malignant epithelial ovarian tumors are detected in late stage, with a 5-year survival rate of about $30 \%$ (2). Ovarian cancer is morphologically classified into four major subtypes: serous, mucinous, clear cell, and endometrioid (3). Mucinous tumors comprise $12-15 \%$ of epithelial ovarian cancers. They are cystic tumors with locules lined with mucin-secreting epithelial cells resembling either endocervical or colonic epithelium. According to the World Health Organization classification, mucinous ovarian tumors are categorized as cystadenomas, borderline tumors, noninvasive intraglandular and intraepithelial carcinomas, invasive carcinomas, and metastatic from other sites. While invasive mucinous carcinomas account for only $10 \%$ of epithelial ovarian cancers, $27 \%$ of patients with stage I epithelial ovarian cancer have mucinous pathology (4). Primary mucinous ovarian tumors are usually distinguished immunohistochemically by positive staining for cytokeratin 7 and negative staining for cytokeratin 20 (5).

Molecular and clinical studies have shown that mucinous ovarian tumors are distinct from other ovarian tumor subyptes in etiologic pathways, response to chemotherapy, and outcome for patients. Unlike the more common serous subtype, mucinous ovarian tumors are not associated with $p 53, B R C A 1$ or $B R C A 2$ mutations, have frequent $k$-ras mutations and modest ratio between the serum markers CA125 and carcinoembryonic antigen CEA (5). Molecular and pathologic studies also support a progression model for the development of mucinous ovarian tumors (6). Transitions between benign and malignant areas are seen in $80 \%$ of malignant mucinous adenocarcinomas. Identical $k$-ras mutations are frequently found in coexisting borderline and invasive epithelia within a mucinous tumor $(7,8)$. Gene expression profiling also identified co-regulated genes shared between cystadenomas and invasive mucinous tumors (9), supporting the view that invasive tumors are evolved from the benign disease. Patients with mucinous ovarian cancer were treated with standard platinum-taxane regimens like the other histologic types. However, advanced mucinous ovarian adenocarcinomas show poor response rates of $26-42 \%$ to first-line platinum-based chemotherapy (10). In addition, many multicenter, population-based, case-control investigations in ovarian cancer have indicated that women with smoking exposure have significant risk of developing mucinous ovarian cancer (11-13). The adjusted odds ratio of smoking exposure to mucinous cancer development ranged from 1.5 to 3.2 , with the current smokers having the highest risk. Similar patterns of elevated risk were not observed among other ovarian histologic types. Extensive studies on the etiology of smoking-related mucinous ovarian cancer should be beneficial for cancer prevention and cancer therapies.

Recent human whole genome sequencing projects have revealed that human cancers are characterized by deregulations of a few core signaling pathways $(14,15)$. Identification of these key signaling pathways is essential for the understanding of pathogenic mechanisms and targeted therapeutic development. It is well known that cancer patient sera contain antibodies that react with a unique group of autologous cellular antigens called tumor-associated antigens $(16,17)$. These autoantibodies, together with $\mathrm{T}$ cell responses, represent the adaptive immune response to tumor-associated antigens in cancer patients (18). Detection of autoantibody reactivity is useful in biomarker discovery and for explaining the role of important pathways in the pathophysiologic development of diseases. Recent studies on tumor-associated antigen- 
induced autoantibodies have demonstrated that the titers of some autoantibodies were significantly elevated several years before the diagnosis of cancer and therefore can serve as an early signal of increased risk of developing cancer (19-21). These characteristics of autoantibodies highlight the potential in evaluating cancer risk and early cancer detection.

There are multiple platforms to compare the whole serum autoantibody repertoires between tumor patients and normal controls (22). The most commonly used method is the use of autoimmune serum in the serological analysis of recombinant cDNA expression libraries (23) or recently of high-density protein microarrays (24). However, this strategy fails to identify autoantibodies that target low abundance proteins and peptides generated from enzymatic cleavages or degradations; recombinant proteins generated from the cDNA library may also lack posttranslational modifications and native configuration necessary for the antibody recognition. Other proteomic methods are either labor intensive or require expensive equipment such as mass spectrometry. (25-27). We have applied an innovative reverse-capture antibody array platform that uses tumor tissue-derived native protein antigens captured on an antibody microarray to profile autoantibody biomarkers in mucinous ovarian cancer plasma samples. We have also analyzed the expression levels of the target antigens that may suggest deregulation of key signaling pathways in the pathogenesis of mucinous ovarian cancer.

\section{MATERIALS AND METHODS}

\subsection{Clinical Specimens}

The ovarian plasma and tissue samples for this study were selected from the $\mathrm{Ob} / \mathrm{Gyn}$ Epidemiology Center and tumor bank at the Laboratory of Gynecologic Oncology at Brigham and Women's Hospital. The plasma samples collected at the Ob/Gyn Epidemiology Center were from a population-based case-control study of ovarian cancer, and a NIH Early Detection Research Network (EDRN) pre-operative/post-operative study. The studies were approved by the Brigham and Women's Hospital and Dartmouth Medical Center's Institutional Review Boards. The normal controls were identified and invited through town books in Massachusetts and Drivers' License lists in New Hampshire and sampled to match the age and residence of the tumor cases. The tumor tissues collected at the Laboratory of Gynecologic Oncology at Brigham and Women's Hospital used protocols approved by the Institutional Review Boards. The histopathological characteristics of the samples were provided by specialists in gynecologic pathology. Patient's consent was obtained before the collection of clinical samples.

\subsection{Reverse capture antibody array profiling using tumor tissue-derived native antigens}

The detailed protocols can be found in published references $(28,29)$, with minor modifications. Briefly, human IgG was isolated from 20 microliters of each cancer plasma sample using the Melon ${ }^{\mathrm{TM}}$ Gel IgG Spin Purification Kit (Pierce Biotechnology, Rockford, IL), according to the manufacturer's instruction. The control IgG was pooled from 20 age-matched healthy women. 100 micrograms of purified cancer and control IgGs were labeled for 45 minutes with $\mathrm{Cy} 3$ and Cy5 mono-Reactive Dye Packs (GE Healthcare Bio-Sciences Corp., Piscataway, NJ), respectively, in Extraction/Labeling Buffer from the Ab Microarray Express Buffer Kit (Clontech Laboratories Inc, Mountain View, CA). Uncoupled Flours were removed by using the Zeba ${ }^{\mathrm{TM}}$ Desalt Spin Columns (Pierce Biotechnology, Rockford, IL). For native antigen preparation, $200 \mathrm{mg}$ of frozen tissue were ground with $0.5 \mathrm{~g}$ of alumina in a mortar. 1-2 ml of prechilled Extracted/Labeling Buffer was added and the paste was centrifuged to collect the supernatant. Protein concentrations of the extracts were determined using microBCA Protein Assay Reagent Kit (Pierce Biotechnology, Rockford, IL). For each microarray incubation, 200 $\mu \mathrm{g}$ of protein extracts were diluted in $5 \mathrm{ml}$ of Incubation Buffer provided by the Ab Microarray Express Buffer Kit (Clontech Laboratories Inc, Mountain View, CA), and applied to the AB 
Microarray-500 slide (Clontech Laboratories Inc, Mountain View, CA). After incubation for $45 \mathrm{~min}$ at room temperature with gentle rocking, the array slide was washed three times with phosphate-buffered saline (PBS). $100 \mu \mathrm{g}$ of each labeled cancer plasma IgG were combined with equal amounts of pooled labeled control IgG and added to each slide and allowed to hybridize at room temperature for 45 minutes. The array was then washed with the Wash Buffers provided by the Ab Microarray Express Buffer kit, once with water, spin-dried, and scanned with a ScanArray 4000XL scanner (Perkin Elmer, Waltham, MA) to obtain Cy5 and $\mathrm{Cy} 3$ images. To confirm the microarray results for each cancer plasma sample, another microarray incubation was performed by swapping the fluorescent dyes in the labeling of cancer and control IgGs.

\subsection{Analysis of the array data and identification of significant autoantibody biomarkers}

The Cy 5 and Cy 3 images of the antibody array experiments of the eleven cancer plasma samples were analyzed by GenePix Pro 6.0 microarray image analysis software (MDS Inc, Toronto, Canada) to produce background-subtracted fluorescence intensity data. $\log _{2}$ transformed normalized fluorescence intensity ratios were median-centered and averaged for the dye swapping experiments. Significance Analysis of Microarrays (SAM) method (30) were first used to identify autoantibodies with statistically significant changes in intensity ratios relative to normal, by assimilating a set of t-tests. Each autoantibody is assigned a test score on the basis of its change in intensity relative to the standard deviation of repeated measurements. The biomarkers were ranked according to the calculated false discovery rate, with a false discovery rate of $3.832 \%$ as the cut-off point. The array data were also analyzed using a normal mixture approach (31) for the detection of autoantibody biomarkers. Transformed z-scores of one-sample t-statistics were clustered into the null group (corresponding to antibodies that are not different between healthy and cancer samples) and the non-null group (corresponding to antibodies that are different between healthy and cancer samples). The ranking of biomarkers was based on the estimated posterior probability that an individual antibody is null. Those biomarkers that were identified as significant in both methods were then entered into the functional annotation and enrichment analysis. The SAM method with two-class t-statistics was performed on the same dataset to identify autoantibody biomarkers that segregate mucinous ovarian cancer patients with and without a smoking history.

\subsection{Functional annotation and enrichment analysis}

Functional annotation and enrichment analysis of the biomarkers was performed using webbased DAVID Functional Annotation Tool (http://david.abcc.ncifcrf.gov/summary.jsp). GenBank accession numbers of the high-ranking biomarkers were submitted to the on-line software to search for significant association of the biomarker clusters with relevant Gene Ontolgoy (GO) terms and Kyoto Encyclopedia of Genes and Genomes (KEGG) pathways.

\subsection{Immunohistochemistry to determine the expression levels of pathway-specific tumor antigens}

A panel of five normal ovarian, ten borderline and fifteen invasive mucinous ovarian tumor tissues were used for the immunohistochemical staining for pathway-specific tumor antigens. 7- $\square \mathrm{m}$ sections were cut from the paraffin-archived tissues, mounted on Superfrost Plus microscopic slides (Fisher Scientific, Pittsburgh, PA), and incubated at $50^{\circ} \mathrm{C}$ for $4 \mathrm{hr}$. The sections were de-paraffinized in xylene and rehydrated with a descending series of ethanol. For antigen unmasking, sections were immersed in antigen-unmasking solution (Vector Laboratories, Burlingame, CA) and boiled in a microwave oven for 10 min. Endogenous peroxidase activity was quenched using $0.3 \% \mathrm{H}_{2} \mathrm{O}_{2}$ in methanol for $20 \mathrm{~min}$. The sections were then blocked with normal horse serum for $20 \mathrm{~min}$ and were subsequently incubated overnight 
with primary antibodies at $4{ }^{\circ} \mathrm{C}$. All primary antibodies were purchased from BD Biosciences (San Jose, CA) and were used in 1:70-100 dilutions. After incubation, VECTASTAIN Elite Avidin-Biotin Complex kit and the substrate diaminobenzidine (DAB) (Vector Laboratories, Burlingame, CA) were used for color development. The sections were counterstained lightly with hematoxylin (Fisher Scientific, Pittsburgh, PA), dehydrated with an ascending series of ethanol, cleared in xylene, and mounted in Permount (Fisher Scientific, Pittsburgh, PA). The staining was quantified with a semiquantitative scoring system. The weighted score was obtained by multiplying the staining intensity score ( $3+$, strong positive stain in cells; $2+$, moderate stain in cells; $1+$, weak stain in cells; 0 , no evidence of stain) and score for the percentage of positive cells ( $3+$, most of cells stained; $2+$, half of cells stained; $1+$, few cells stained; 0 , no cells stained). Two observers scored the slides independently, and the scores for all cases were compared for discrepancies. The data obtained were analyzed by Mann-Whitney test with MINITAB statistical software (Minitab, State College, PA) as the data were not normally distributed. The staining of a tumor sample is considered as significantly different from that of the normal ovaries when $P<0.05$.

\section{RESULTS}

\subsection{Autoantibody profiling of mucinous plasma by reverse capture antibody array platform}

We explored the use of an innovative "reverse capture antibody array" method to profile the autoantibodies of eleven cases of mucinous ovarian cancer plasma samples. The clinicopathologic information of the patients is listed in Table S1. The "reverse capture antibody array" method is based on the concept of dual-antibody sandwich ELISA assay (28, 32). This method (Figure S1) uses native protein antigens extracted from a pool of six mucinous tumor tissues and captured by the monoclonal antibodies on a commercial high-density antibody microarray as "baits" to bind fluorescently labeled human immunoglobulins (IgGs) purified from patient and control plasma samples (29). The competitive binding between patient and control antibodies to the antigens is visualized by fluorescence intensities of the two dyes.

The results of a representative array experiment are presented in Figure 1. To control for any labeling artifacts and confirm the differential antibody profiles, a second microarray hybridization was performed by reversing the fluorescent dyes in the labeling of antibodies. Authentic difference in the antibody titer will show reverse color change on the same spots in the two arrays (Figure 1). Analysis of antibody array data using the analysis package "Significance Analysis of Microarrays" (SAM) (30) resulted in the identification of thirtyseven potential autoantibody biomarkers that are significantly elevated in the mucinous cases as compared to normal controls (Figure 2a, and Table S2), and six autoantibody biomarkers that can differentiate smoking and nonsmoking cases (Figure 2b). Furthermore, we also analyzed the data using a normal mixture approach (31) for the detection of autoantibody biomarkers, which is based on the clustering of transformed z-scores of t-statistics into the null group (corresponding to antibodies that are not different between healthy and cancer samples) and the non-null group (corresponding to antibodies that are different between healthy and cancer samples). SAM generated false discovery rate for the identified marker list, whereas the mixture approach provided the estimation of the posterior probability that an individual antibody is null and hence the ranking of antibodies in decreasing order of the posterior probabilities. Tables S2 and S3 present respectively the statistics of SAM, and the top ranking autoantibodies of normal mixture model, respectively, for the autoantibodies that were elevated in the mucinous cases. There are thirty-five such antibody biomarkers that are identified as significant with the use of both SAM and the normal mixture approach (Table 1). 


\subsection{Annotation analysis of the targets of identified antibody biomarkers}

To interrogate the potential functions and the associated pathways of the targets of identified antibody biomarkers in ovarian tumors, we performed a functional annotation and enrichment analysis of the thirty-five autoantibody biomarkers using DAVID Functional Annotation Tool (33). Functional annotation of the antibody targets suggested that mucinous ovarian plasma samples are enriched with antibodies that target nucleoproteins, as in many autoimmune diseases, as well as antibodies that target intracellular cell organization and signaling proteins (Table 2). In particular, search in Kyoto Encyclopedia of Genes and Genomes (KEGG) indicated significant enrichment of six elevated tumor autoantibodies that target antigens involved in integrins-mediated pathway, and three tumor autoantibodies that target antigens in Wnt signaling pathways (Table 3, and Figure S2).

\subsection{Elevated expression of the pathway-associated antibody antigens in mucinous ovarian tumors}

The finding of autoantibodies in cancer plasmas that target integrins and Wnt signaling pathways may suggest that these two pathways are deregulated in mucinous ovarian cancer. To corroborate this finding, we employed antibodies that are specific to the marker antigens in the immunohistochemical staining of a panel of archived ovarian specimens that include normal ovaries, borderline and invasive mucinous ovarian tumors. The results of immunohistochemistry (Figure 3) showed significant overexpression of all pathway-associated tumor antigens except GIT1 in mucinous ovarian tumors, suggesting that these pathways might be aberrantly activated in mucinous ovarian tumors and the host immune system might have heightened reactivities with epitopes presented by these antigens.

\section{DISCUSSION}

The immune system of cancer patients actively monitors and elicits T-cell (34) and autoantibody response to tumor-associated antigens $(16,17)$. Detection of autoantibody reactivity is useful in biomarker discovery and can reveal the identity of antigens that might play a role in the pathophysiologic development of diseases. Some studies have shown that the presence of serum autoantibodies is associated with changes in the antigens in human cancers $(21,35)$. Hence, screening of autoantibodies, whose levels significantly correlate with disease status, may be beneficial to both diagnostic and therapeutic advances.

Several array-based screening platforms have been reported for autoantibody screening (24, 36). However, these protein microarrays employed recombinant proteins that may not have the same posttranslational modifications and native configurations recognized by the autoantibodies. It has been reported that removal of the carbohydrate moieties of ThomsenFriedenreich antigen caused the loss of binding of autoantibodies $(37,38)$. Therefore, strategies that employ native antigens derived from diseased materials may add significant value to identify the authentic autoantibody-antigen reactivities. We have applied an innovative reverse-capture antibody array platform that uses tumor tissue-derived native protein antigens captured on an antibody microarray (29) to profile autoantibody biomarkers. The use of two methods to analyze the array data has allowed us to identify thirty-five autoantibodies that were elevated in cancer cases (Table 1). Functional annotation and enrichment analysis of these autoantibody biomarkers have shown that the tumor antigen targets for these autoantibodies are composed of nucleoproteins and intracellular cell organization and signaling proteins. Significantly, we found an enrichment of nine autoantibody antigens in the integrin pathway that regulates actin cytoskeleton and cell invasion (Figure S2a), and beta-catenin-mediated Wnt signaling pathway (39) that is important during development and oncogenesis (Figure $\mathrm{S} 2 \mathrm{~b})$. Immunohistochemistry has revealed significant overexpression of eight of the nine antigens in both borderline and invasive mucinous ovarian tumors (Figure 3), While the GIT1 
antigen did not show significant overexpression in mucinous ovarian tumors, it is possible that the antigen underwent other changes such as mutations during pathogenesis that were not revealed by immunohistochemistry. Integrin receptors for fibronectin are important for the response of ovarian carcinoma to matrix microenvironment and metastasis $(40,41)$. Some markers such as alpha 2-integrins are involved in the dissemination of mucinous cystadenocarcinoma (42), and the expression of Wnt signaling protein beta-catenin was found distinctively high in the membrane and cytoplasm of mucinous tumors $(43,44)$. Hence overexpression of tumor antigens involved in these two pathways in mucinous ovarian tumors may suggest that deregulation of both integrin and Wnt signaling pathways are important to pathogenic development of human mucinous ovarian cancer and likely stimulate the immune system to produce the autoantibody biomarkers identified by this autoantibody screen.

Epidemiologic studies have indicated that women with tobacco exposure have significant risk of developing mucinous ovarian cancer (11-13). We therefore have analyzed the reverse capture antibody array data to determine if there are autoantibody biomarkers that can distinguish between smoking and nonsmoking mucinous cancers. Two-class SAM analysis has identified six antibodies that are significantly different between these two groups of mucinous cancer samples (Figure 2b). These antibody targets play important roles in the homeostasis of different biological processes such as DNA repair (three prime repair exonuclease 1), glucose metabolism (Aralar 1), and cell cycle regulation (cyclin-dependent kinase 4). Moreover, these proteins have been reported to be involved in autoimmunity (45-48). We are currently performing studies to further evaluate if the identified marker targets can reveal any mechanistic differences underlying smoking and nonsmoking mucinous ovarian cancer.

In conclusion, our autoantibody profiling in mucinous ovarian cancer using the innovative reverse capture antibody array platform has identified thirty-five autoantibody biomarkers. Nine of the autoantibody targets are associated with tumor antigens involved in integrins and Wnt signaling pathways. Autoantibody profiling may have substantial utility in identifying key signaling pathways that are deregulated in cancer and other diseases.

\section{Supplementary Material}

Refer to Web version on PubMed Central for supplementary material.

\section{Acknowledgments}

This study was supported by a generous grant from the Flight Attendant Medical Research Institute (FAMRI), and also partly from a pilot grant from Dana-Farber/Harvard Cancer Center Ovarian SPORE, and Women's Cancer Program from Dana-Farber Cancer Institute. N.R. was supported by Ruth N. White Gynecologic Oncology Research Fellowship. The laboratory is also supported by Gillette Center for Women's Cancer, Ovarian Cancer Research Foundation, Adler Foundation, Inc., and Friends of Dana Farber Cancer Institute.

We also thank Ian Ma and Anita Ng for the help with data management.

\section{REFERENCES}

1. American Cancer Society. Cancer Facts and Figures. American Cancer Society, Inc; 2004. 2004

2. Bast, RC., Jr.; Boyer, CM.; Olt, GJ.; Berchuck, A.; Soper, JT.; Clarke-Pearson, D., et al. Identification of marker for early detection of epithelial ovarian cancer. Chapman and Hall Medical; London, England: 1990.

3. Serov, SF.; Scullt, RE. Histological typing of ovarian tumors. World Health Organization; Geneva: 1993. 
4. Vergote I, De Brabanter J, Fyles A, Bertelsen K, Einhorn N, Sevelda P, et al. Prognostic importance of degree of differentiation and cyst rupture in stage I invasive epithelial ovarian carcinoma. Lancet 2001;357(9251):176-82. [PubMed: 11213094]

5. Harrison ML, Jameson C, Gore ME. Mucinous ovarian cancer. Int J Gynecol Cancer 2008;18(2):209_ 14. [PubMed: 17624989]

6. Puls LE, Powell DE, DePriest PD, Gallion HH, Hunter JE, Kryscio RJ, et al. Transition from benign to malignant epithelium in mucinous and serous ovarian cystadenocarcinoma. Gynecol Oncol 1992;47 (1):53-7. [PubMed: 1427402]

7. Ichikawa Y, Nishida M, Suzuki H, Yoshida S, Tsunoda H, Kubo T, et al. Mutation of K-ras protooncogene is associated with histological subtypes in human mucinous ovarian tumors. Cancer Res 1994;54(1):33-5. [PubMed: 8261457]

8. Mok SC, Bell DA, Knapp RC, Fishbaugh PM, Welch WR, Muto MG, et al. Mutation of K-ras protooncogene in human ovarian epithelial tumors of borderline malignancy. Cancer Res 1993;53(7): 1489-92. [PubMed: 8384077]

9. Wamunyokoli FW, Bonome T, Lee JY, Feltmate CM, Welch WR, Radonovich M, et al. Expression profiling of mucinous tumors of the ovary identifies genes of clinicopathologic importance. Clin Cancer Res 2006;12(3 Pt 1):690-700. [PubMed: 16467078]

10. Hess V, A'Hern R, Nasiri N, King DM, Blake PR, Barton DP, et al. Mucinous epithelial ovarian cancer: a separate entity requiring specific treatment. J Clin Oncol 2004;22(6):1040-4. [PubMed: 15020606]

11. Marchbanks PA, Wilson H, Bastos E, Cramer DW, Schildkraut JM, Peterson HB. Cigarette smoking and epithelial ovarian cancer by histologic type. Obstet Gynecol 2000;95(2):255-60. [PubMed: 10674590]

12. Modugno F, Ness RB, Cottreau CM. Cigarette smoking and the risk of mucinous and nonmucinous epithelial ovarian cancer. Epidemiology 2002;13(4):467-71. [PubMed: 12094103]

13. Zhang Y, Coogan PF, Palmer JR, Strom BL, Rosenberg L. Cigarette smoking and increased risk of mucinous epithelial ovarian cancer. Am J Epidemiol 2004;159(2):133-9. [PubMed: 14718214]

14. Parsons DW, Jones S, Zhang X, Lin JC, Leary RJ, Angenendt P, et al. An integrated genomic analysis of human glioblastoma multiforme. Science 2008;321(5897):1807-12. [PubMed: 18772396]

15. Jones S, Zhang X, Parsons DW, Lin JC, Leary RJ, Angenendt P, et al. Core signaling pathways in human pancreatic cancers revealed by global genomic analyses. Science 2008;321(5897):1801-6. [PubMed: 18772397]

16. Chinni SR, Falchetto R, Gercel-Taylor C, Shabanowitz J, Hunt DF, Taylor DD. Humoral immune responses to cathepsin D and glucose-regulated protein 78 in ovarian cancer patients. Clin Cancer Res 1997;3(9):1557-64. [PubMed: 9815843]

17. Korneeva I, Bongiovanni AM, Girotra M, Caputo TA, Witkin SS. Serum antibodies to the 27-kd heat shock protein in women with gynecologic cancers. Am J Obstet Gynecol 2000;183(1):18-21. [PubMed: 10920302]

18. Gnjatic S, Atanackovic D, Jager E, Matsuo M, Selvakumar A, Altorki NK, et al. Survey of naturally occurring CD4+ T cell responses against NY-ESO-1 in cancer patients: correlation with antibody responses. Proc Natl Acad Sci U S A 2003;100(15):8862-7. [PubMed: 12853579]

19. Frenkel K, Karkoszka J, Glassman T, Dubin N, Toniolo P, Taioli E, et al. Serum autoantibodies recognizing 5-hydroxymethyl-2'-deoxyuridine, an oxidized DNA base, as biomarkers of cancer risk in women. Cancer Epidemiol Biomarkers Prev 1998;7(1):49-57. [PubMed: 9456243]

20. Hu JJ, Chi CX, Frenkel K, Smith BN, Henfelt JJ, Berwick M, et al. Alpha-tocopherol dietary supplement decreases titers of antibody against 5-hydroxymethyl-2'-deoxyuridine (HMdU). Cancer Epidemiol Biomarkers Prev 1999;8(8):693-8. [PubMed: 10744129]

21. Lubin R, Zalcman G, Bouchet L, Tredanel J, Legros Y, Cazals D, et al. Serum p53 antibodies as early markers of lung cancer. Nat Med 1995;1(7):701-2. [PubMed: 7585154]

22. Caron M, Choquet-Kastylevsky G, Joubert-Caron R. Cancer immunomics using autoantibody signatures for biomarker discovery. Mol Cell Proteomics 2007;6(7):1115-22. [PubMed: 17376768]

23. Wang Y, Han KJ, Pang XW, Vaughan HA, Qu W, Dong XY, et al. Large scale identification of human hepatocellular carcinoma-associated antigens by autoantibodies. J Immunol 2002;169(2): 1102-9. [PubMed: 12097419] 
24. Hudson ME, Pozdnyakova I, Haines K, Mor G, Snyder M. Identification of differentially expressed proteins in ovarian cancer using high-density protein microarrays. Proc Natl Acad Sci U S A 2007;104 (44):17494-9. [PubMed: 17954908]

25. Hong SH, Misek DE, Wang H, Puravs E, Giordano TJ, Greenson JK, et al. An autoantibody-mediated immune response to calreticulin isoforms in pancreatic cancer. Cancer Res 2004;64(15):5504-10. [PubMed: 15289361]

26. Tomaino B, Cappello P, Capello M, Fredolini C, Ponzetto A, Novarino A, et al. Autoantibody Signature in Human Ductal Pancreatic Adenocarcinoma. J Proteome Res 2007;6(10):4025-4031. [PubMed: 17824682]

27. Madoz-Gurpide J, Kuick R, Wang H, Misek DE, Hanash SM. Integral protein microarrays for the identification of lung cancer antigens in sera that induce a humoral immune response. Mol Cell Proteomics. 2007

28. Ehrlich JR, Qin S, Liu BC. The 'reverse capture' autoantibody microarray: a native antigen-based platform for autoantibody profiling. Nat Protoc 2006;1(1):452-60. [PubMed: 17406268]

29. Ehrlich, JR.; Tang, L.; Caiazzo, RJ., Jr.; Cramer, DW.; Ng, S-K.; Ng, S-W., et al. The reverse capture autoantibody microarray: an innovative approach to profiling the autoantibody response to tissuederived native antigens. In: Ehrlich, JR.; Liu, BC., editors. Tissue Proteomics- Pathways, Biomarkers, and Drug Discovery. Humana Press; New Jersey: 2008. p. 175-192.

30. Tusher VG, Tibshirani R, Chu G. Significance analysis of microarrays applied to the ionizing radiation response. Proc Natl Acad Sci U S A 2001;98(9):5116-21. [PubMed: 11309499]

31. McLachlan GJ, Bean RW, Jones LB. A simple implementation of a normal mixture approach to differential gene expression in multiclass microarrays. Bioinformatics 2006;22(13):1608-15. [PubMed: 16632494]

32. Qin S, Qiu W, Ehrlich JR, Ferdinand AS, Richie JP, O'Leary MP, et al. Development of a “reverse capture" autoantibody microarray for studies of antigen-autoantibody profiling. Proteomics 2006;6 (10):3199-209. [PubMed: 16596707]

33. Dennis G Jr. Sherman BT, Hosack DA, Yang J, Gao W, Lane HC, et al. DAVID: Database for Annotation, Visualization, and Integrated Discovery. Genome Biol 2003;4(5):P3. [PubMed: 12734009]

34. Tatsumi T, Herrem CJ, Olson WC, Finke JH, Bukowski RM, Kinch MS, et al. Disease stage variation in CD4+ and CD8+ T-cell reactivity to the receptor tyrosine kinase EphA2 in patients with renal cell carcinoma. Cancer Res 2003;63(15):4481-9. [PubMed: 12907621]

35. Zhang J, Chan EK. Autoantibodies to IGF-II mRNA binding protein p62 and overexpression of p62 in human hepatocellular carcinoma. Autoimmun Rev 2002;1(3):146-53. [PubMed: 12849008]

36. Chatterjee M, Mohapatra S, Ionan A, Bawa G, Ali-Fehmi R, Wang X, et al. Diagnostic markers of ovarian cancer by high-throughput antigen cloning and detection on arrays. Cancer Res 2006;66(2): 1181-90. [PubMed: 16424057]

37. Lang GA, Yeaman GR. Autoantibodies in endometriosis sera recognize a Thomsen-Friedenreichlike carbohydrate antigen. J Autoimmun 2001;16(2):151-61. [PubMed: 11247641]

38. Yeaman GR, Collins JE, Lang GA. Autoantibody responses to carbohydrate epitopes in endometriosis. Ann N Y Acad Sci 2002;955:174-82. discussion 199-200, 396-406. [PubMed: 11949946]

39. Novak A, Dedhar S. Signaling through beta-catenin and Lef/Tcf. Cell Mol Life Sci 1999;56(56):52337. [PubMed: 11212302]

40. Shield K, Riley C, Quinn MA, Rice GE, Ackland ML, Ahmed N. Alpha2beta1 integrin affects metastatic potential of ovarian carcinoma spheroids by supporting disaggregation and proteolysis. $\mathrm{J}$ Carcinog 2007;6:11. [PubMed: 17567918]

41. Ahmed N, Riley C, Rice G, Quinn M. Role of integrin receptors for fibronectin, collagen and laminin in the regulation of ovarian carcinoma functions in response to a matrix microenvironment. Clin Exp Metastasis 2005;22(5):391-402. [PubMed: 16283482]

42. Kishikawa T, Sakamoto M, Ino Y, Kubushiro K, Nozawa S, Hirohashi S. Two distinct patterns of peritoneal involvement shown by in vitro and in vivo ovarian cancer dissemination models. Invasion Metastasis 1995;15(12):11-21. [PubMed: 7545653] 
43. Sarrio D, Moreno-Bueno G, Sanchez-Estevez C, Banon-Rodriguez I, Hernandez-Cortes G, Hardisson $\mathrm{D}$, et al. Expression of cadherins and catenins correlates with distinct histologic types of ovarian carcinomas. Hum Pathol 2006;37(8):1042-9. [PubMed: 16867867]

44. Kildal W, Risberg B, Abeler VM, Kristensen GB, Sudbo J, Nesland JM, et al. beta-catenin expression, DNA ploidy and clinicopathological features in ovarian cancer: a study in 253 patients. Eur J Cancer 2005;41(8):1127-34. [PubMed: 15911235]

45. Marzo N, Ortega S, Stratmann T, Garcia A, Rios M, Gimenez A, et al. Cyclin-dependent kinase 4 hyperactivity promotes autoreactivity in the immune system but protects pancreatic cell mass from autoimmune destruction in the nonobese diabetic mouse model. J Immunol 2008;180(2):1189-98. [PubMed: 18178859]

46. Yang YG, Lindahl T, Barnes DE. Trex 1 exonuclease degrades ssDNA to prevent chronic checkpoint activation and autoimmune disease. Cell 2007;131(5):873-86. [PubMed: 18045533]

47. Hur JW, Sung YK, Shin HD, Park BL, Cheong HS, Bae SC. TREX1 polymorphisms associated with autoantibodies in patients with systemic lupus erythematosus. Rheumatol Int 2008;28(8):783-9. [PubMed: 18092167]

48. Delunardo F, Conti F, Margutti P, Alessandri C, Priori R, Siracusano A, et al. Identification and characterization of the carboxy-terminal region of Sip-1, a novel autoantigen in Behcet's disease. Arthritis Res Ther 2006;8(3):R71. [PubMed: 16611372] 


\section{Mix 1 Cy5 Control} Cy3 Case
Mix 2 Cy5 Case Cy3 Control
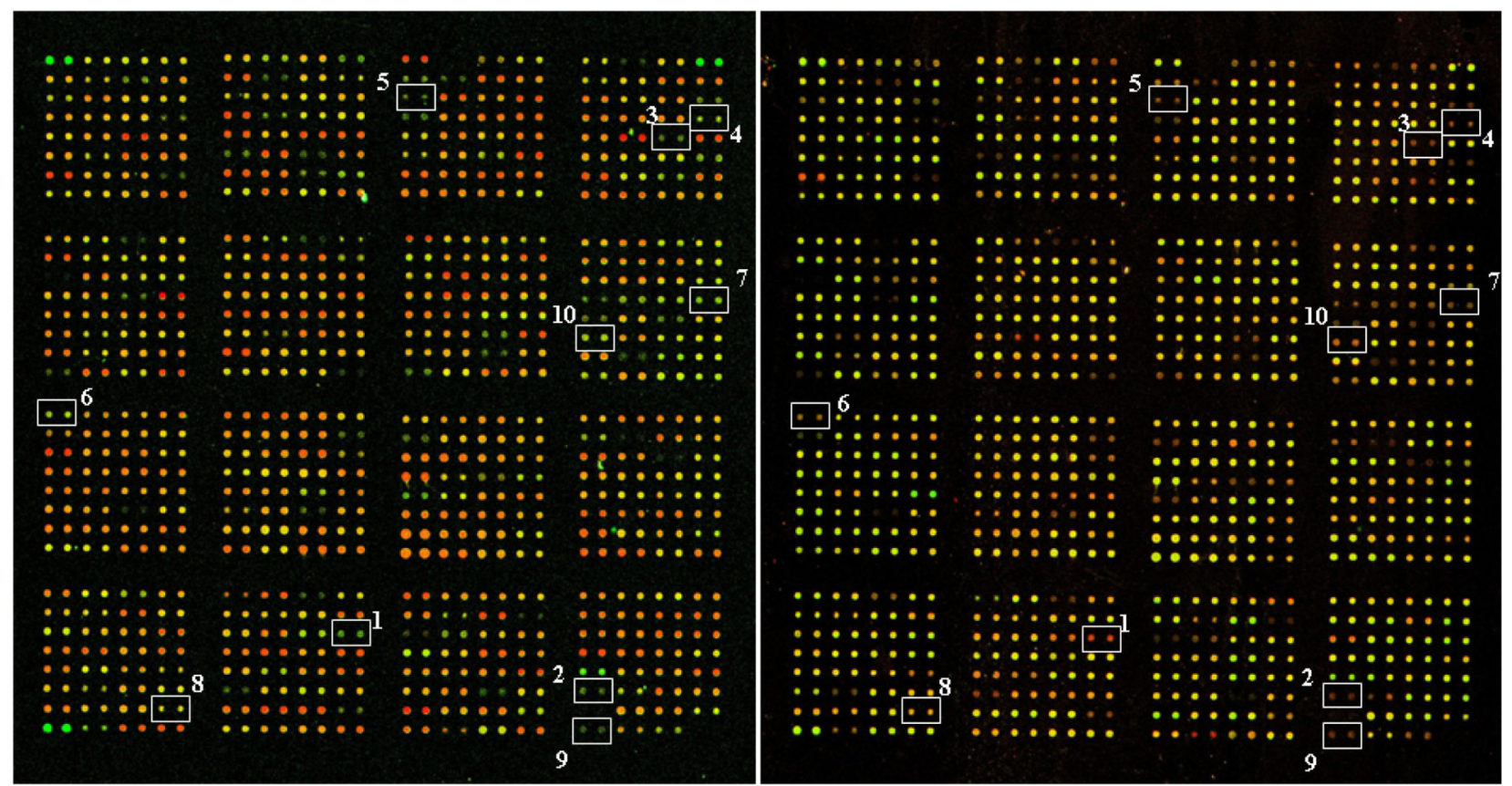

1. CSE1 chromosome segregation 1-like

3. Casein kinase 1, epsilon

2. Topoisomerase (DNA) II alpha, $170 \mathrm{kDa}$

5. Non-metastatic cells 1, protein (NM23A)

4. G protein-coupled receptor 51

7. Synt axin binding protein 5 (tomosyn)

6. Ras-GTPase-activating protein $\mathrm{SH3}$-domain-binding protein

8. Integrin, alpha 2 (CD49B, alpha 2 subunit of VLA-2 receptor)

9. Dystrophia myotonica-protein kinase

10. RAS $\mathrm{p} 21$ protein activator (GTPase activating protein) 1

Figure 1. Representative figure of an antibody array experiment

Antibodies that are elevated in cancer plasma are green in array 1 and red in array 2. Some of the identified autoantibody biomarkers are marked as shown. 


\section{Figure 2a.}
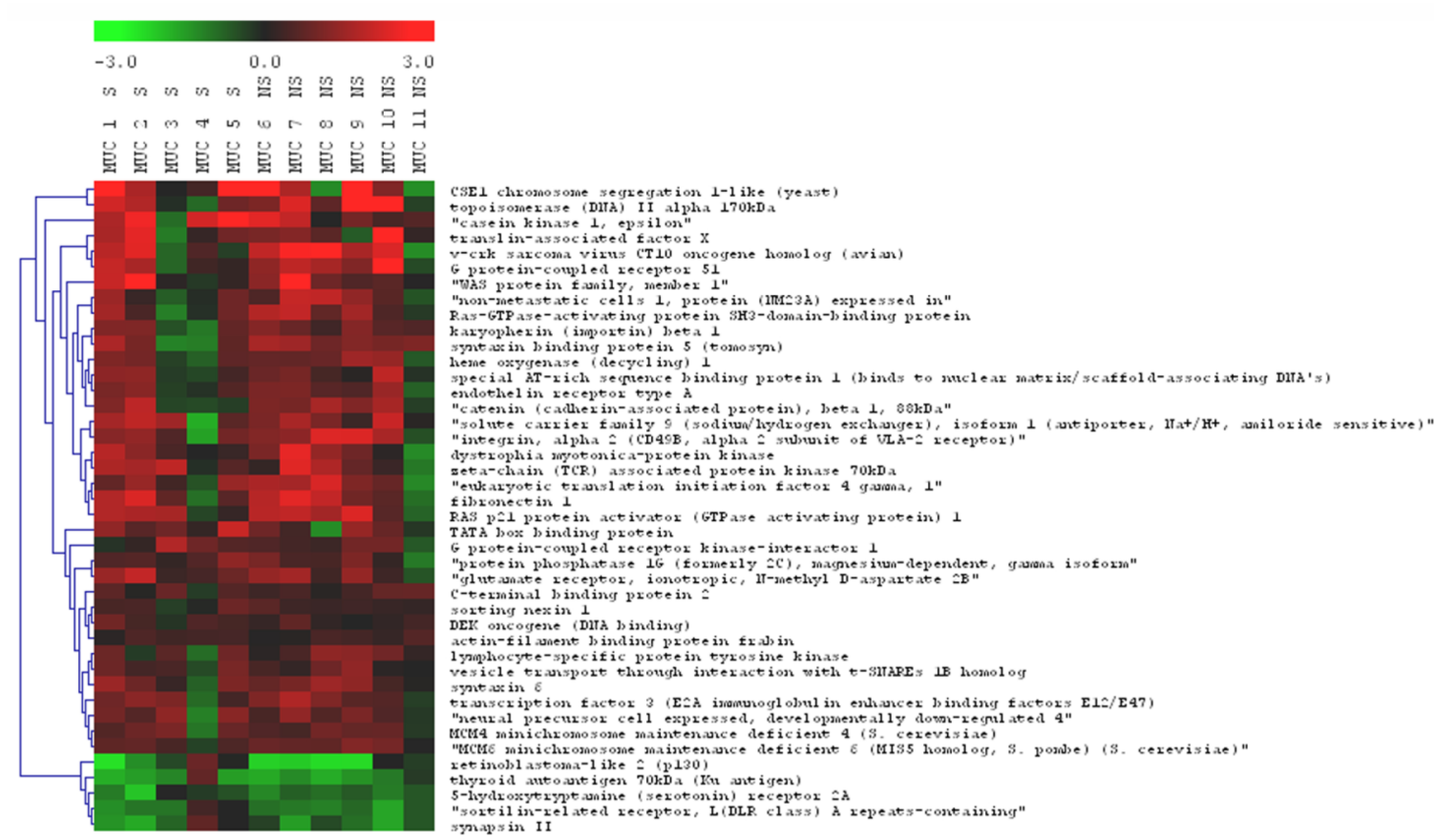

Figure 2b.

survival of motor neuron protein interacting protein 1

three prime reprix exomiclease 1
chromogranin $\mathrm{B}$ (secretogravin 1$)$

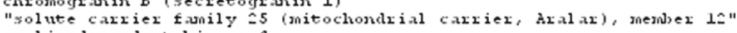

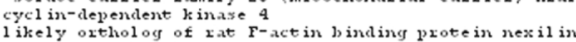

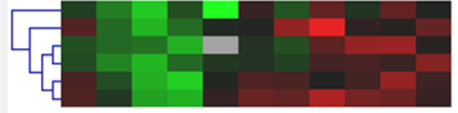

Figure 2. Autoantibody biomarkers for mucinous ovarian cancer determined by "Significance Analysis of Microarrays"

The heat maps show (a) autoantibodies that are significantly different between cancer cases and healthy control; and (b) autoantibodies that are significantly different between smoking and non-smoking group. 


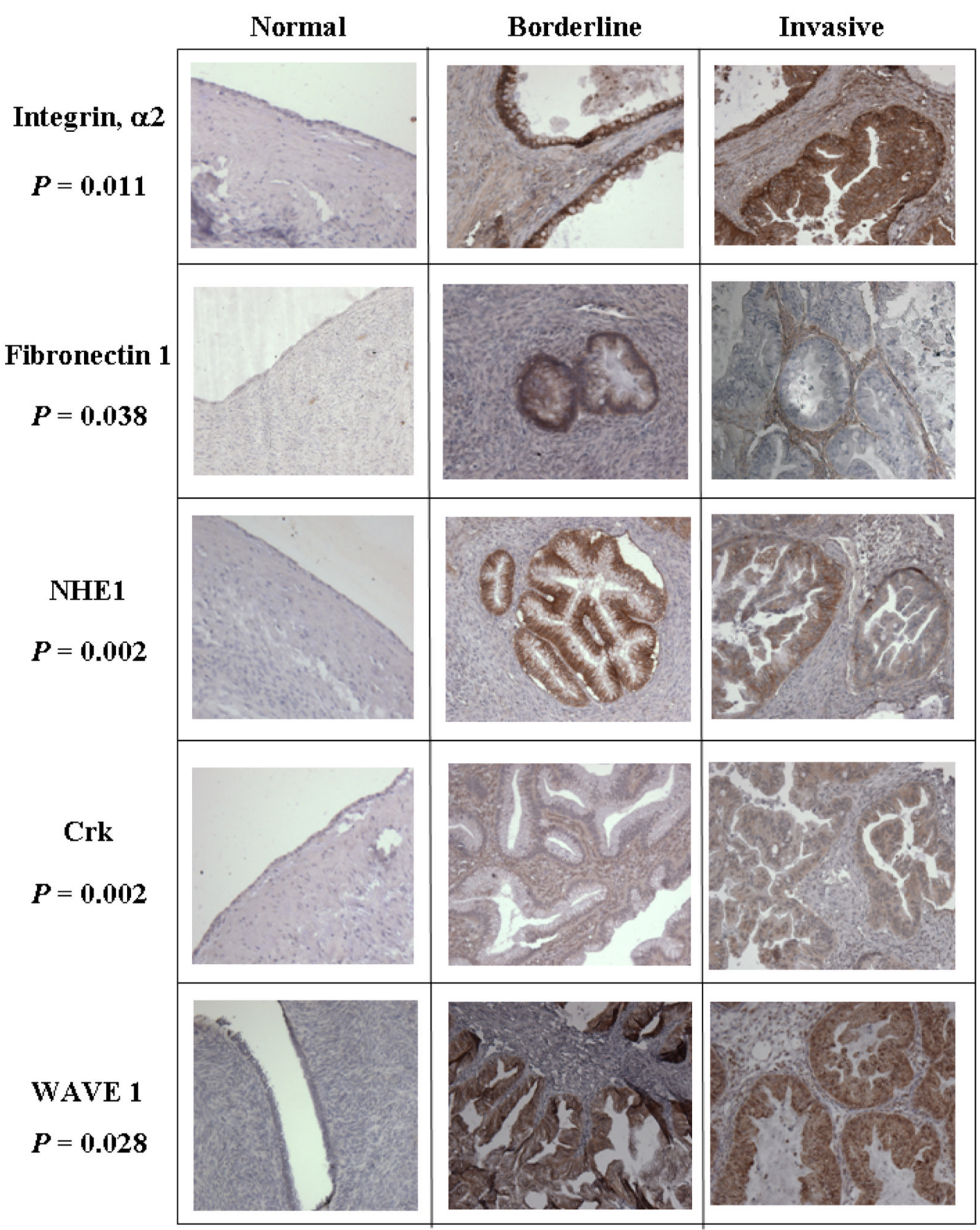




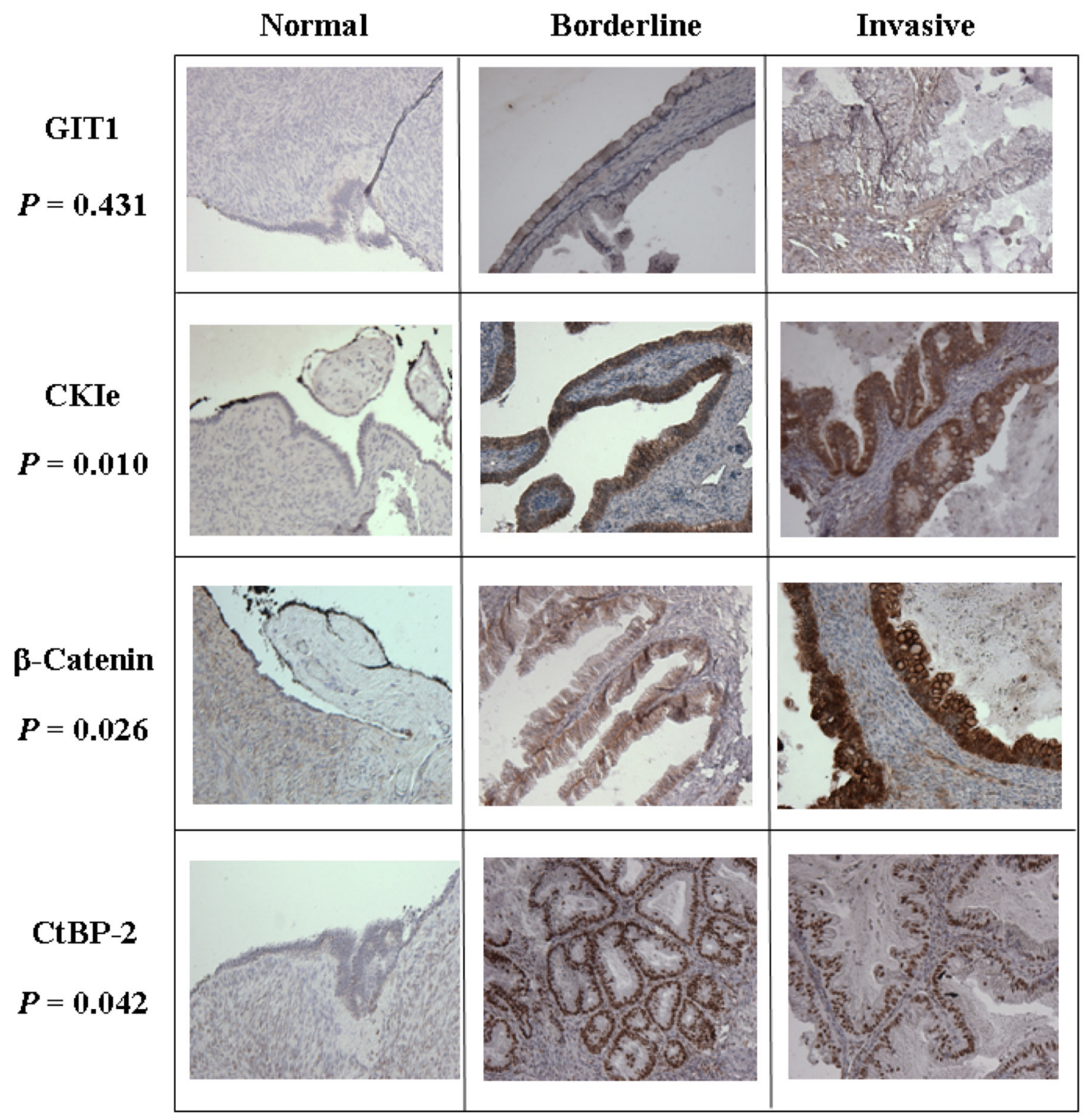

Figure 3. Immunohistochemistry for the expression of pathway-specific tumor antigens Representative micrographs of immunohistochemical staining of normal, borderline and invasive mucinous ovarian tumor sections are shown. The names of the tumor antigens and the $P$-values for the Mann-Whitney analysis of the immunohistochemical results are shown on the left. 
Table 1

The list of thirty-five autoantibody biomarkers that are significant with both "Significance Analysis of Microarrays" and the normal mixture approaches.

\begin{tabular}{|c|c|c|}
\hline ID & Accession Number & $\begin{array}{l}\text { Fold-changes } \\
\text { relative to normal }\end{array}$ \\
\hline casein kinase 1 , epsilon & P49674 & 2.529 \\
\hline CSE1 chromosome segregation 1-like (yeast) & P55060 & 2.49 \\
\hline topoisomerase (DNA) II alpha 170KDa & P11388 & 2.462 \\
\hline $\begin{array}{l}\text { v-crk sarcoma virus CT10 oncogene homolog } \\
\text { (avian) }\end{array}$ & P46108 & 2.254 \\
\hline $\begin{array}{l}\text { RAS p21 protein activator (GTPase activating } \\
\text { protein)1 }\end{array}$ & P20936 & 2.085 \\
\hline G protein-coupled receptor 51 & O75899 & 2.053 \\
\hline WAS protein family, member 1 & Q92558 & 2.032 \\
\hline fibronectin 1 & P02751 & 1.969 \\
\hline $\begin{array}{l}\text { integrin, alpha } 2(\mathrm{CD} 49 \mathrm{~B} \text {, alpha } 2 \text { subunit of } \\
\text { VLA-2 receptor) }\end{array}$ & P17301 & 1.895 \\
\hline $\begin{array}{l}\text { solute carrier family } 9 \text { (sodium/hydrogen } \\
\text { exchanger), isoform } 1 \text { (antiporter, } \mathrm{Na}+\mathrm{H}+\text {, } \\
\text { amiloride sensitive) }\end{array}$ & P19634 & 1.834 \\
\hline zeta-chain (TCR) associated protein kinase $70 \mathrm{kDa}$ & P43403 & 1.812 \\
\hline translin-associated factor $\mathrm{X}$ & Q99598 & 1.793 \\
\hline $\begin{array}{l}\text { eukaryotic translation initiation factor } 4 \text { gamma, } \\
1\end{array}$ & Q04637 & 1.775 \\
\hline $\begin{array}{l}\text { glutamate receptor, ionotropic, N-methyl D- } \\
\text { aspartate } 2 B\end{array}$ & Q13224 & 1.753 \\
\hline syntaxin binding protein 5 (tomosyn) & Q5T5C0 & 1.667 \\
\hline dystrophia myotonica-protein kinase & Q09013 & 1.659 \\
\hline syntaxin 6 & $\mathrm{O} 43752$ & 1.623 \\
\hline $\begin{array}{l}\text { Ras-GTPase-activating protein SH3-domain- } \\
\text { binding protein }\end{array}$ & Q13283 & 1.617 \\
\hline $\begin{array}{l}\text { catenin (cadherin-associated protein), beta } 1, \\
88 \mathrm{kDa}\end{array}$ & P35222 & 1.615 \\
\hline $\begin{array}{l}\text { non-metastatic cells } 1 \text {, protein (NM23A) } \\
\text { expressed in }\end{array}$ & $\mathrm{P} 15531$ & 1.589 \\
\hline $\begin{array}{l}\text { transcription factor } 3 \text { (E2A immunoglobulin } \\
\text { enhancer binding factors E12/E47) }\end{array}$ & P15923 & 1.583 \\
\hline TATA box binding protein & P20226 & 1.534 \\
\hline $\begin{array}{l}\text { neural precursor cell expressed, developmentally } \\
\text { down-regulated } 4\end{array}$ & P46934 & 1.496 \\
\hline heme oxygenase (decycling) 1 & P09601 & 1.47 \\
\hline $\begin{array}{l}\text { special AT-rich sequence binding protein } 1 \text { (binds } \\
\text { to neclear matrix/scaffold-associating DNA's) }\end{array}$ & Q01826 & 1.468 \\
\hline endothelin receptor type A & P25101 & 1.468 \\
\hline karyopherin (importin) beta 1 & Q14974 & 1.452 \\
\hline G protein-coupled receptor kinase-interactor 1 & Q9Y2X7 & 1.418 \\
\hline $\begin{array}{l}\text { MCM4 minichromosome maintenance deficient } 4 \\
\text { (S. cerevisiae) }\end{array}$ & P33991 & 1.404 \\
\hline
\end{tabular}




\begin{tabular}{|l|c|c|}
\hline ID & Accession Number & $\begin{array}{c}\text { Fold-changes } \\
\text { relative to normal }\end{array}$ \\
lymphocyte-specific protein tyrosine kinase & P06239 & 1.398 \\
protein phosphatase 1G (formerly 2C), & O15355 & 1.388 \\
magnesium-dependent, gamma isoform & Q9UEU0 & 1.375 \\
vesicle transport through interaction with t- & P56545 & 1.335 \\
C-terminal binding protein 2 & P35659 & 1.264 \\
DEK oncogene (DNA binding) & Q13596 & 1.232 \\
sorting nexin 1 & & \\
\hline
\end{tabular}


Table 2

Functional annotation and enrichment analysis of the autoantibody targets.

\begin{tabular}{|l|c|c|c|}
\hline Nuclear Proteins (N=17) & & & \\
\hline Term & Count $^{\boldsymbol{a}}$ & Fold-Enrichment $^{\boldsymbol{b}}$ & P_Value $^{\boldsymbol{c}}$ \\
\hline Nucleobase, nucleoside, nucleotide and & 11 & 2.6 & $1.20 \mathrm{E}-05$ \\
nucleic acid metabolism & 3 & 54.4 & $1.20 \mathrm{E}-03$ \\
DNA-dependent ATPase activity & 7 & 4.1 & $3.20 \mathrm{E}-03$ \\
DNA-binding & 5 & 6 & $6.20 \mathrm{E}-03$ \\
Cell proliferation & 8 & 3 & $7.10 \mathrm{E}-03$ \\
Regulation of transcription & 5 & 5.8 & $7.30 \mathrm{E}-03$ \\
Cell death & 3 & 8.9 & $3.90 \mathrm{E}-02$ \\
Response to DNA damage stimulus & & & \\
\hline
\end{tabular}

Cytoplasmic and Plasma Membrane Proteins (N=29)

\begin{tabular}{l|l|l|l|l}
\hline Term & Count $^{a}$ & Fold-Enrichment & $b$ & P_Value $c$
\end{tabular}

Cytoplasmic and Plasma Membrane Proteins (N=29)

Intracellular signaling cascade

Receptor complex

Cell communication

Vesicle-mediated transport

cell proliferation

Hydrolase activity, acting on ester bonds

Apoptosis

Cell Surface Receptor-linked Signal

Transduction

\begin{tabular}{|c|c|c|}
12 & 4.4 & $2.20 \mathrm{E}-05$ \\
4 & 25.4 & $4.60 \mathrm{E}-04$ \\
16 & 2.1 & $1.50 \mathrm{E}-03$ \\
6 & 6.5 & $1.70 \mathrm{E}-03$ \\
7 & 4.8 & $2.20 \mathrm{E}-03$ \\
6 & 4.8 & $6.50 \mathrm{E}-03$ \\
6 & 4.2 & $1.10 \mathrm{E}-02$ \\
8 & 2.3 & $3.80 \mathrm{E}-02$ \\
\hline
\end{tabular}

Annotated gene functions were determined by searches in Gene Ontology.

$a_{\text {the number of antigens belonging to an annotation term. }}$

$b$ The ratio of the number of antigens described by the term category over total number of antigens in the list relative to the ratio of proteins with the same term category in the human genome background

$c$, modified Fisher Exact P-value to measure the enrichment in annotation terms. 
Table 3

Enrichment analysis of the autoantibody targets in pathways by searches in Kyoto Encyclopedia of Genes and Genomes (KEGG) Pathway Databases.

\begin{tabular}{|l|c|c|c|l|}
\hline Term & Count $^{\boldsymbol{a}}$ & Fold-Enrichment $^{\boldsymbol{b}}$ & P_Value $^{\boldsymbol{c}}$ & Genes \\
\hline Wnt signaling pathway & 3 & 12 & $1.70 \mathrm{E}-02$ & $\begin{array}{l}\text { Catenin (cadherin-associated } \\
\text { protein), beta 1, 88kda } \\
\text { Casein kinase 1, epsilon } \\
\text { C-terminal binding protein 2 }\end{array}$ \\
\hline $\begin{array}{l}\text { Regulation of actin } \\
\text { cytoskeleton }\end{array}$ & 6 & 5.9 & $2.10 \mathrm{E}-03$ & $\begin{array}{l}\text { Integrin, alpha 2 (CD49B, } \\
\text { alpha 2 subunit of VLA-2 } \\
\text { receptor) } \\
\text { Fibronectin 1 } \\
\text { NHE-1 } \\
\text { V-crk sarcoma virus CT10 } \\
\text { oncogene homolog (avian) } \\
\text { G protein-coupled receptor } \\
\text { kinase-interactor 1 } \\
\text { WAS protein family, member } \\
1\end{array}$ \\
& & & & \\
\hline
\end{tabular}

Annotated gene functions were determined by searches in Gene Ontology.

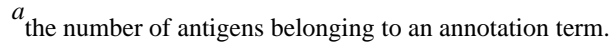

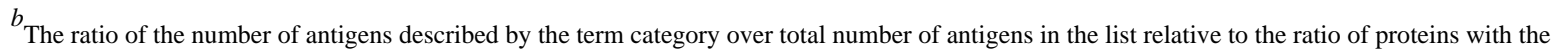
same term category in the human genome background

${ }^{c}$, modified Fisher Exact P-value to measure the enrichment in annotation terms. 